\title{
CYP2D6 Metabolism in Frail Elderly Compared to Non-Frail Elderly: A Pilot Feasibility Study
}

\author{
F. L. Opdam ${ }^{1,6} \cdot$ A. S. Modak $^{2}$ - S. P. Mooijaart ${ }^{5} \cdot$ M. Louwerens ${ }^{3} \cdot$ \\ M. W. M. de Waal ${ }^{4}$ H. Gelderblom ${ }^{6}$ - H.-J. Guchelaar ${ }^{1}$
}

Published online: 23 November 2015

(C) The Author(s) 2015. This article is published with open access at Springerlink.com

\begin{abstract}
Background Frailty is a clinical phenotype that is associated with adverse health outcomes. Since frail patients may be more prone for adverse drug events and about $15-20 \%$ of commonly prescribed drugs are metabolized by CYP2D6, we hypothesized that CYP2D6 metabolism is decreased in frail patients compared with healthy subjects. Methods The ${ }^{13} \mathrm{C}$-dextromethorphan breath test (DM-BT) was used to determine CYP2D6 phenotype using ${ }^{13} \mathrm{C}$ dextromethorphan $\left({ }^{13} \mathrm{C}-\mathrm{DM}\right)$ as a probe. Eleven frail and 22 non-frail (according to the Fried criteria) subjects aged 70-85 years were phenotyped for CYP2D6.

Results Despite inequalities in CYP2D6 genotype between frail and non-frail subjects, the CYP2D6 gene activity score was equally distributed between the two groups $(1.33 \pm 0.50$ vs. $1.28 \pm 0.752)$. In male patients,
\end{abstract}

F. L. Opdam

f.1.opdam@lumc.nl

1 Department of Clinical Pharmacy and Toxicology, LUMC, Leiden, The Netherlands

2 Cambridge Isotope Laboratories, Inc., Andover, MA, USA

3 Department of Endocrinology, LUMC, Leiden, The Netherlands

4 Department of Public Health and Primary Care, LUMC, Leiden, The Netherlands

5 Department of Gerontology and Geriatrics, LUMC, Leiden, The Netherlands

6 Department of Clinical Oncology, K1-64, Leiden University Medical Center, PO Box 9600, 2300 RC Leiden, The Netherlands no difference in total and free serum testosterone levels was observed between frail and non-frail men. Serum dehydroepiandrostenedione sulfate (DHEAS) levels were lower in frail subjects $(1.56 \mu \mathrm{mol} / \mathrm{L})$ compared with nonfrail subjects $(2.36 \mu \mathrm{mol} / \mathrm{L})$, but the difference was not significant $(p=0.15)$. Body mass index was significantly correlated to CYP2D6 phenotype, whereas frailty score and individual parameters of frailty, Karnofsky score, and activities of daily living score were not significantly correlated to CYP2D6 phenotype. Although there was no difference in CYP2D6 phenotype observed between frail mean \pm standard deviation (mean $\pm \mathrm{SD}$ ) area under the curve for delta over baseline values $(0-2 \mathrm{~h})\left(\mathrm{AUC}_{\mathrm{DOB} 2 \mathrm{~h}}\right)$ $319 \pm 169 \% \mathrm{~min}]$ and non-frail subjects (mean $\pm \mathrm{SD}$ $\mathrm{AUC}_{\mathrm{DOB} 2 \mathrm{~h}} 298 \pm 159 \% \mathrm{~min}$ ), the present sample size is considered too small to draw any firm conclusions regarding a potential phenoconversion of CYP2D6 in frail elderly as compared with healthy subjects.

Conclusion Frail and non-frail subjects did not differ in CYP2D6 phenotype, taking into account that the precalculated sample size was not achieved. Further studies with more patients are needed in order to adequately understand a possible correlation.

\section{Key Points}

Frail subjects may be more prone to adverse drug reactions.

The ${ }^{13} \mathrm{C}$-dextromethorphan breath test is a phenotype test to determine CYP2D6 enzyme activity.

Frail and non-frail subjects did not differ in CYP2D6 phenotype. 


\section{Introduction}

Frailty is a clinical phenotype that is associated with adverse health outcomes $[1,2]$ and is characterized by an excessive reduction of lean body mass, sarcopenia, chronic undernourishment, reduced function, and poor endurance. Frailty might influence the pharmacokinetics and pharmacodynamics of drugs [3]. Studies investigating the effect of frailty on the pharmacokinetics of drugs in older people are scarce. In the limited studies published, the interpretation of the results is complicated by inconsistent assessment of frailty.

From a pathological point of view, there is an association between inflammation and frailty [4]. Frailty was associated with higher inflammatory markers such as interleukin-6 (IL-6) and lower pseudocholinesterase (dibucaine) activity [4]. Inflammation has the potential to downregulate drug metabolism and transporter pathways $[4,9]$, reducing the systemic clearance of some drugs.

Indeed, sulfation of metoclopramide [7] and glucuronidation of acetaminophen [6] were significantly decreased in frail elderly compared with fit elderly. In contrast, very old ( $>80$ years) as well as frail people were able to maintain the ability to metabolize CYP3A4 substrates in a phenotyping study using the erythromycin breath test (ERBT) [5].

CYP2D6 has been involved in the metabolism of approximately $15-20 \%$ of all drugs such as $\beta$-blockers, antipsychotics (like haloperidol), most selective serotonin reuptake inhibitors (SSRIs), and antitumor agents such as tamoxifen and gefitinib, and is therefore a drug metabolizing enzyme that could potentially increase the risk of drug side effects in frail elderly.

Studies on ageing and CYP2D6 phenotype are conflicting: there is no evidence that slow debrisoquine (test probe for CYP2D6) metabolizers are more common at older age [10]. Clinically, however, older people using propranolol as a probe drug are at greater risk of adverse reactions if they have lower CYP2D6 enzyme activity. There was more than a $50 \%$ reduction in clearance of total propranolol in older patients deficient in the CYP2D6 pathway compared with young subjects [11]. Therefore, there is a need to understand the factors that determine heterogeneity of metabolism in elderly, which might be partly attributed to frailty, in order to individualize pharmacotherapy. To date, no phenotyping studies have been reported on the CYP2D6 enzyme and frailty.

The goal of this investigation was to study CYP2D6 phenotype in frail and non-frail elderly, to test the hypothesis that frailty is associated with decreased CYP2D6-mediated metabolism. The ${ }^{13} \mathrm{C}$-dextromethorphan breath test (DM-BT) was used to determine the CYP2D6 phenotype with limited breath sampling using ${ }^{13} \mathrm{C}$-dextromethorphan $\left({ }^{13} \mathrm{C}\right.$-DM $)$ as a phenotype probe
[12]. Leeder et al. [12] developed a single-point DM-BT to specifically phenotype CYP2D6 in a simple, rapid way. ${ }^{13} \mathrm{C}$-labeled DM is metabolized by CYP2D6 via $O$ demethylation. The released methyl group is involved in the formation of ${ }^{13} \mathrm{CO}_{2}$ that is released in expired breath over time. DM-BT resulted in 30 healthy subjects correlating well with the urinary ${ }^{13} \mathrm{C}$-dextromethorphan/dextrorphan (DM/DX) ratio, an alternative way to phenotype CYP2D6. By defining the CYP2D6 poor metabolizer (PM) phenotype by a single-point DM-BT result at $t=50 \mathrm{~min}$ [delta over baseline at $t=50 \mathrm{~min}\left(\mathrm{DOB}_{50}\right) \leq 0.5 \%$ ], sensitivity and specificity of DM-BT to detect PM was 100 and $95 \%$, respectively, using either genotype or DM/DX ratio as the "gold" standard" [12]. In our study, the DMBT was used to determine CYP2D6 phenotype with limited breath sampling using ${ }^{13} \mathrm{C}$-DM as a phenotype probe.

\section{Methods}

\subsection{Population}

To assess the impact of frailty on CYP2D6 metabolism, and to exclude age as a possible confounder, it was chosen to select frail and non-frail subjects in the age range of 70-85 years, who were recruited from the outpatient clinic at the Leiden University Medical Center. The subjects were referred by general practitioners from the Leiden region, or were recruited by advertisements. The protocol was approved by the institutional review boards of the Leiden University Medical Center, The Netherlands. All subjects provided written informed consent. Since no data exist regarding the phenotype parameter $\mathrm{DOB}_{2 \mathrm{~h}}$, the power calculation was based on existing $\mathrm{DOB}_{50}$ values from our prior study [8], given that $\mathrm{DOB}_{50}$ is considered to sufficiently correlate with $\mathrm{DOB}_{2 \mathrm{~h}}$. To achieve $80 \%$ power at a 0.05 significance level in order to detect a hypothesized difference in CYP2D6 phenotype parameter $\mathrm{DOB}_{50}$ of 0.8 , between frail and non-frail elderly, the calculated sample size was 42 (21 frail, 21 non-frail patients). Blood samples were collected to determine CYP2D6 genotype by the Amplichip array (Amplichip, Roche). CYP2D6 genotype was translated into an ultrarapid (UM) (e.g., $\mathrm{XN} * 1$ ), extensive (EM) (e.g., *1/*1), heterozygous extensive (hetEM) (e.g., $* 1 / * 4)$, intermediate (IM) (e.g., *41/*41) or poor metabolizer $(\mathrm{PM})(* 4 / * 4)$ predicted phenotype. CYP2D6 activity score was determined for each patient according to the method introduced by Gaedigk et al. [13].

\subsection{Baseline Evaluation}

Patients were interviewed to assess physical function, demographics, self-estimated health, weight loss, energy 
expenditure, frequency of falls, medications used, and a diagnosis of Parkinson's, cognitive impairment, cardiovascular events (myocardial infarction, stroke and peripheral vascular disease), cancer, diabetes, renal disease, and hearing and visual impairment. Comorbidity was defined as the presence of three or more of these conditions. Physical function was ascertained by Karnofsky score and questionnaires regarding activities of daily living (ADL). Subjects' length and weight were recorded. Blood samples were collected under fasting conditions, to analyze alanine aminotransferase (ALAT), aspartate aminotransferase (ASAT), alkaline phosphatase, lactate dehydrogenase, total bilirubin, creatinine, dibucaine number (pseudocholinesterase), dehydroepiandrostenedione sulfate (DHEAS), (free) testosterone and sex hormone-binding globulin (SHBG) by the Clinical Chemical Laboratory of the Leiden University Medical Center. Cognitive function was assessed with the Mini-Mental State Examination [14]. Physical function included maximal grip strength (kilograms) in the dominant hand (three measures averaged), using a Jamar ${ }^{\circledR}$ hand-held dynamometer (Sammons Preston Rolyan, Bolingbrook, Illinois, USA), assessment of time to walk $4 \mathrm{~m}$ at usual walking speed and assessment of five times sit-to-stand test (FTSTS).

\subsection{Fried Frailty Score}

Subjects were tested for frailty using the Fried [1] criteria. A patient was identified as a frail subject when at least three Fried criteria were met, while a subject was considered non-frail when none of the criteria were met, in order to discriminate sufficiently between the subgroups. A phenotype of frailty was identified by the presence of three or more of the following determinants of frailty:

1. Unintentional weight loss of $\geq 5 \mathrm{~kg}$ in the prior year or, at follow-up, of $\geq 5 \%$ of body weight in the prior year.

2. Hand grip strength of $<30 \mathrm{~kg}$ (men) or $<18 \mathrm{~kg}$ (women).

3. Normal walking speed of less than $0.76 \mathrm{~m} / \mathrm{s}$ (more than $6 \mathrm{~s}$ for $4 \mathrm{~m}$ ).

4. Poor energy expenditure in the last 3 months, reflected in more than $4 \mathrm{~h}$ sitting a day, less than 1 stroll/month, and no cycling or jogging.

5. The presence of self-reported exhaustion, identified by a positive answer to two questions from the Center for Epidemiologic Studies Depression (CES-D) scale [15]:

- Do you struggle to get going?

- Does everything you do take effort?

The number of frailty characteristics present was identified in each subject. Subjects were identified as non-frail by the absence of all Fried criteria (Table 1).

\subsection{Inclusion and Exclusion Criteria}

Men and women aged 70-85 years with a body mass index (BMI) between 20 and $30 \mathrm{~kg} / \mathrm{m}^{2}$ were included in the study. Subjects were excluded from the study when the investigator identified the following: acute illness, metastasized cancer, inability or unwillingness to fast overnight prior to the study session, inability or unwillingness to abstain from drinking alcohol for $24 \mathrm{~h}$ prior to the DM-BT, a diagnosis of severe asthma or severe chronic obstructive pulmonary disease (COPD), the existence of metabolic or gastrointestinal disorders that influence absorption and/or gastric emptying, a demonstrated adverse reaction to previous DM exposure, impaired hepatic function as defined by $\geq$ grade 3 Aspartate aminotransferase (AST), alkaline phosphatase or total bilirubin or a history of liver cirrhosis, stage IV renal insufficiency defined by an modification of diet in renal disease (MDRD) of $<30 \mathrm{~mL} / \mathrm{min}$, use of medication known to slow gastric emptying or gastrointestinal motility within $24 \mathrm{~h}$ of the breath test, use of medication inhibiting or inducing CYP2D6 and/or mono-amine oxidase (MAO) inhibitors in the last 2 weeks, and use of DM cough syrup/ tablets within $24 \mathrm{~h}$ of the breath test.

\subsection{DM-BT}

The DM-BT was used to determine CYP2D6 phenotype. Participants were asked to fast for at least $12 \mathrm{~h}$ and abstain from alcohol intake for $24 \mathrm{~h}$ prior to the administration of the DM-BT. During the breath test, patients were observed and potential side effects were recorded. A baseline breath sample was collected into a 1.3 -L first breath bag prior to first administration of two Alka-Seltzer Gold (ASG) ${ }^{\circledR}$ tablets and $50 \mathrm{mg}=24 \mathrm{~mL}$ of a $2.07 \mathrm{mg} / \mathrm{mL}{ }^{13} \mathrm{C}-\mathrm{DM}$ formulation (Cambridge Isotope Laboratories Inc. ${ }^{\circledR}$, Andover, Massachusetts, USA).

Breath samples were collected into a 1.3-L breath bag at 30, 40, 50, 60, 90 and 120 min post dose. Following the collection of the breath samples, the breath was analyzed for ${ }^{13} \mathrm{CO}_{2} /{ }^{12} \mathrm{CO}_{2}$ ratio using a POCone ${ }^{\circledR}$ (Otsuka Pharmaceutical Ltd., Tokyo, Japan) spectrophotometer. A DOB value was calculated for each time point, reflecting CYP2D6 activity [12]: $\mathrm{DOB} \quad(t=x \mathrm{~min})=1000 \times\left[\left({ }^{13} \mathrm{CO}_{2} /{ }^{12} \mathrm{CO}_{2}\right)\right.$ post dose $-\left({ }^{13} \mathrm{CO}_{2} /{ }^{12} \mathrm{CO}_{2}\right)$ baseline]/RPDB, where DOB is expressed in units of $\Delta$ per mille (\%o), and RPDB $=0.012373$ is ${ }^{13} \mathrm{C} /{ }^{12} \mathrm{C}$ in PDB (international standard Pee Dee Belemnite). Using the trapezoidal method, the area under the curve (AUC) of DOB versus time (min) was calculated for each subject.

\subsection{Data Analysis}

Data are presented as mean with SD or range for summary statistics. Statistical analyses of data were done with IBM 
Table 1 Demographic and frailty characteristics of the study population

\begin{tabular}{|c|c|c|}
\hline & Frail & Non-frail \\
\hline Number $(N)$ & 11 & 22 \\
\hline Men & 6 & 12 \\
\hline Women & 5 & 10 \\
\hline Age (years), mean (min-max) & $74.5(70-79)$ & $78.6(70-85)$ \\
\hline BMI $\left(\mathrm{kg} / \mathrm{m}^{2}\right)$, mean $(\min -\max )$ & $26.1(19.1-32.5)$ & $25.4(19.9-30.6)$ \\
\hline Predicted phenotype & 9 & 18 \\
\hline $\mathrm{PM}$ & 0 & 3 \\
\hline $\mathrm{IM}$ & 6 & 7 \\
\hline EM & 3 & 8 \\
\hline Gene activity score mean \pm SD & $1.33 \pm 0.50$ & $1.28 \pm 0.752$ \\
\hline \multicolumn{3}{|l|}{ Comorbidities $(N)$} \\
\hline 0 & 2 & 18 \\
\hline 1 & 1 & 2 \\
\hline 2 & 2 & 2 \\
\hline 3 & 2 & 0 \\
\hline 4 & 3 & 0 \\
\hline 5 & 1 & 0 \\
\hline Karnofsky score, mean (range) & $77.3(60-90)$ & $96.8(90-100)$ \\
\hline Frailty score $^{\mathrm{a}}$, mean (range) & $3.36(3-4)$ & 0 \\
\hline $\mathrm{ADL}^{\mathrm{b}}$, mean (range) & $0.8(0-3)$ & $0.1(0-1)$ \\
\hline MMSE score ${ }^{\mathrm{c}}$, mean (range) & $28.8(27-30)$ & $29(27-30)$ \\
\hline \multicolumn{3}{|l|}{ Max. grip strength $(\mathrm{kg})^{\mathrm{d}}$, mean (range) } \\
\hline Men & $31.3(26.0-42.0)$ & $35.0(22.1-51.0)$ \\
\hline Women & $18.2(8.0-28.0)$ & $28.2(20.0-39.0)$ \\
\hline 4-m walking time $(s)^{\mathrm{e}}$, mean (range) & $7.9(4.7-25.8)$ & $4.6(2.8-5.8)$ \\
\hline Chair-stand test $(\mathrm{s})^{\mathrm{f}}$, mean (range) & $15.9(10.8-29.3)$ & $13.2(8.3-20)$ \\
\hline \multicolumn{3}{|l|}{ Laboratory investigations } \\
\hline ALAT $(\mathrm{U} / \mathrm{L})^{\mathrm{g}}$, mean (range) & $15.4(7.4-27.5)$ & $10.1(4.0-18.4)$ \\
\hline ASAT $(\mathrm{U} / \mathrm{L})^{\mathrm{h}}$, mean (range) & $32.1(14.9-56)$ & $25.2(14.0-50.4)$ \\
\hline LDH (U/L) $)^{\mathrm{i}}$ mean (range) & $220(129-407)$ & $206(139-349)$ \\
\hline Bilirubin $(\mu \mathrm{mol} / \mathrm{L})^{\mathrm{j}}$, mean (range) & $12.2(4.5-28)$ & $10.7(6.3-16.5)$ \\
\hline Creatinine $(\mu \mathrm{mol} / \mathrm{L})^{\mathrm{k}}$, mean (range) & $103(84-130)$ & $106(61-164)$ \\
\hline Dibucaine $^{1}$, mean (range) & $76.8(73.1-78.1)$ & $77.0(75.6-78.7)$ \\
\hline Testosterone $(\mathrm{nmol} / \mathrm{L})^{\mathrm{m}}$, mean (range) & $19.3(16.5-22.8)$ & $15.6(5.6-30.0)$ \\
\hline Free testosterone $(\mathrm{pmol} / \mathrm{L})^{\mathrm{n}}$, mean (range) & $240(163-415)$ & $235(114-364)$ \\
\hline
\end{tabular}


Table 1 continued

\begin{tabular}{|c|c|c|}
\hline & Frail & Non-frail \\
\hline DHEAS $(\mu \mathrm{mol} / \mathrm{L})^{\mathrm{o}}$, mean (range) & $1.56(0.42-3.47)$ & $-5.43)$ \\
\hline \multicolumn{3}{|c|}{$\begin{array}{l}A D L \text { activities of daily living, } A L A T \text { alanine aminotransferase, } A S A T \text { aspartate aminotransferase, } B M I \text { body } \\
\text { mass index, } C E S \text { - } D \text { center for epidemiologic studies depression, } D H E A S \text { dehydroepiandrostenedione sul- } \\
\text { fate, } E M \text { extensive metabolizer, } I M \text { intermediate metabolizer, } M M S E \text { Mini-Mental State Examination, } P M \\
\text { poor metabolizer, } S D \text { standard deviation }\end{array}$} \\
\hline \multicolumn{3}{|c|}{$\begin{array}{l}\text { Fried frailty score (ref): the total sum for the presence of each item: unintentional weight loss of } \geq 5 \mathrm{~kg} \text { in } \\
\text { the prior year or, at follow-up, of } \geq 5 \% \text { of body weight in prior year; hand grip strength of }<30 \mathrm{~kg} \text { (men) or } \\
<18 \mathrm{~kg} \text { (women); normal walking speed of less than } 0.76 \mathrm{~m} / \mathrm{s} \text { (more than } 6 \mathrm{~s} \text { for } 4 \mathrm{~m} \text { ); poor energy } \\
\text { expenditure in the last } 3 \text { months reflected in more than } 4 \mathrm{~h} \text { sitting a day, less than } 1 \text { stroll/month, and no } \\
\text { cycling or jogging; the presence of self-reported exhaustion, identified by a positive answer to two ques- } \\
\text { tions from the CES-D scale (Weissman et al. [15]): Do you struggle to get going? Does everything you do } \\
\text { take effort? }\end{array}$} \\
\hline \multicolumn{3}{|c|}{$\begin{array}{l}\text { b ADL: one point for each for the inability to independently perform the following } 9 \text { functions: bathing, } \\
\text { shopping, cooking, eating, dressing, using toilet, transferring, sexual performance, and controlling conti- } \\
\text { nence, as reported by all participants }\end{array}$} \\
\hline \multicolumn{3}{|c|}{$\begin{array}{l}\text { The MMSE or Folstein test is a brief } 30 \text {-point questionnaire test that is used to screen for cognitive } \\
\text { impairment. It is commonly used in medicine to screen for dementia. It is also used to estimate the severity } \\
\text { of cognitive impairment and to follow the course of cognitive changes in an individual over time, thus } \\
\text { making it an effective way to document an individual's response to treatment. Any score greater than or } \\
\text { equal to } 27 \text { points (out of } 30 \text { ) indicates normal cognition. Below this, scores can indicate severe ( } \leq 9 \\
\text { points), moderate (10-18 points) or mild (19-24 points) cognitive impairment }\end{array}$} \\
\hline \multicolumn{3}{|c|}{$\begin{array}{l}\text { d Maximal grip strength (kilograms) in the dominant hand ( } 3 \text { measures averaged), using a Jamar }{ }^{\circledR} \text { hand- } \\
\text { held dynamometer }\end{array}$} \\
\hline \multicolumn{3}{|c|}{ e Time in seconds to walk $4 \mathrm{~m}$ at normal speed } \\
\hline \multicolumn{3}{|c|}{$\begin{array}{l}{ }^{f} \text { Time in seconds for a subject to stand up } 5 \text { times from a chair with the arms in a crossed position in front } \\
\text { of the chest }\end{array}$} \\
\hline \multicolumn{3}{|c|}{ g Serum ALAT, reference: men 0-45 U/L, women 0-34 U/L } \\
\hline \multicolumn{3}{|c|}{ h Serum ASAT, reference: men 0-35 U/L, women 0-31 U/L } \\
\hline \multicolumn{3}{|c|}{${ }^{\mathrm{i}}$ Serum lactate dehydrogenase, reference: $0-248 \mathrm{U} / \mathrm{L}$} \\
\hline \multicolumn{3}{|c|}{ j Serum bilirubin, reference: $3.1-6.4 \mu \mathrm{mol} / \mathrm{L}$} \\
\hline \multicolumn{3}{|c|}{${ }^{\mathrm{k}}$ Serum creatinine, reference: men 64-104 $\mu \mathrm{mol} / \mathrm{L}$, women $49-90 \mu \mathrm{mol} / \mathrm{L}$} \\
\hline \multicolumn{3}{|l|}{${ }^{1}$ Serum dibucaine number: $70-100$} \\
\hline \multicolumn{3}{|c|}{ m Serum testosterone (men only), reference: $8-50 \mathrm{nmol} / \mathrm{L}$} \\
\hline \multicolumn{3}{|c|}{${ }^{\mathrm{n}}$ Serum free testosterone (men only), reference: $120-750 \mathrm{pmol} / \mathrm{L}$} \\
\hline & & \\
\hline
\end{tabular}

SPSS Statistics, version 22. Comparisons of demographic data were done by use of the unpaired Student's $t$ test. Analyses of DM-BT data were done by use of Analysis of variance (ANOVA) or regression analyses as indicated.

\section{Results}

\subsection{Study Participants}

All patients were Caucasians. There were difficulties in recruiting frail patients in our study; due to their frailty, many subjects were not able to come to the outpatient clinic and often appointments were cancelled. In five patients, the study procedures were conducted at the subjects' home to overcome this issue. Thirty-five (13 frail, 22 non-frail) patients were initially enrolled for the study. Two frail patients were found to be ineligible according to the pre-specified Fried criteria. Eventually 33 patients (11 frail and 22 non-frail) were enrolled in this study. Of the 22 nonfrail patients, 12 were male and ten were female, and of the 11 frail, six were male and five were female. The patients' mean $( \pm \mathrm{SD})$ age was 77.3 years $( \pm 4.3)$ and the mean $( \pm \mathrm{SD})$ weight was $76.1 \mathrm{~kg}( \pm 12.7)$. Age, weight and BMI did not differ between frail and non-frail patients.

The predicted CYP2D6 phenotypes (following the genotyping result) were not equally distributed: in the frail group, 0/11 subjects had a PM predicted phenotype, whereas in the non-frail group, the PM phenotype occurred in $3 / 22$ subjects. The IM predicted phenotype occurred in $6 / 11$ frail versus 7/22 non-frail subjects, whereas the EM predicted phenotype was almost equally distributed among the two groups (frail 3/11 and non-frail 8/22). However, the mean gene activity score did not differ between the two 
groups [1.33 (SD 0.50) vs. 1.28 (SD 0.752)]. The CYP2D6 gene activity score significantly $(p=0.010)$ correlated ( $r=0.486$, Pearson correlation) to the CYP2D6 phenotype, consistent with previous findings from our study in patients who were treated with tamoxifen in the adjuvant setting. In this study [8], CYP2D6 gene activity score explained $48.7 \%$ of variance in the $\log$ transformed CYP2D6 phenotype by DM-BT $\left(r^{2}=0.487, p<0.001\right.$, $n=63)$.

In frail subjects, the total number of comorbidities was higher compared with non-frail subjects. More than $50 \%$ of frail subjects had three or more comorbidities, compared with $0 \%$ in the non-frail subjects. Consistent with the presence of frailty, the frailty score was higher (3.36 vs. 0 , $p<0.001)$ and the Karnofsky score was lower in frail subjects compared with non-frail subjects (77.3 vs. $96.8 \%$, $p<0.001)$. None of the frail subjects had a $100 \%$ Karnofsky score. No difference in daily activities and cognitive function (by means of a Mini-Mental State Examination) were observed between the two groups.

Hand grip strength was slightly lower in frail men compared with non-frail men, but the difference was not statistically significant ( 31.3 vs. $35.0 \mathrm{~kg}, p=0.317$ ). For women, however, the difference in hand grip strength was more obvious between the two groups $(18.2 \mathrm{~kg}$ in frail vs. $28.2 \mathrm{~kg}$ in non-frail patients, $p=0.01)$. In frail patients, a significantly lower walking speed was observed compared with non-frail subjects ( $7.9 \mathrm{~s}$ for $4 \mathrm{~m}$ vs. $4.6 \mathrm{~s}, p=0.017$ ), more or less consistent with the pre-specified cut-off value of $6 \mathrm{~s}$ in the Fried criteria for frail subjects. The chair-stand test was performed at a lower speed in frail compared with non-frail subjects (15.9 vs. $13.2 \mathrm{~s}$ ), but the difference was not significant $(p=0.119)$.

Liver and renal function did not significantly differ between the two groups. No difference in the dibucaine number was observed between the two groups.

In male patients, no difference in total and free serum testosterone levels was observed between frail and nonfrail men. Serum DHEAS levels were lower in frail subjects $(1.56 \mu \mathrm{mol} / \mathrm{L})$ compared with non-frail subjects $(2.36 \mu \mathrm{mol} / \mathrm{L})$, but the result was not significant $(p=0.15)$. Smoking was not reported in any subject. Use of low amounts of alcoholic beverages was reported in two patients in the non-frail subgroup.

\subsection{DM-BT Results}

Both healthy and frail subjects were able to carry out the breath test according to applicable procedures. No difference in CYP2D6 activity was observed between frail and non-frail subjects [area under the curve for delta over baseline values $(0-2 \mathrm{~h})\left(\mathrm{AUC}_{\mathrm{DOB} 2 \mathrm{~h}}\right) 319 \pm 169 \% \mathrm{~min}$ in frail vs. $298 \pm 159 \%$ min, $p=0.728$, Fig. 1]. Also, no difference in CYP2D6 activity was observed between frail men and non-frail men and between frail women and nonfrail women, respectively. Recruitment of subjects was limited to patients aged 70-85 years in order to assess the influence on frailty without the interference of age as a possible confounder. Indeed, it was shown that in the chosen small age frame, no correlation between age and CYP2D6 phenotype by DM-BT was detected $\left(r^{2}=0.008\right.$, $p=0.631$ for age vs. $\left.\mathrm{AUC}_{\mathrm{DOB} 2 \mathrm{~h}}\right)$. CYP2D6 activity by DM-BT was significantly higher in women than in men $\left(\mathrm{AUC}_{\mathrm{DOB} 2 \mathrm{~h}} 362 \pm 162\right.$ vs. $252 \pm 142 \%$ min, $p=0.036$, Table 2) for the whole group. In the non-frail group, there was a non-significant $(p=0.059)$ trend towards a higher CYP2D6 phenotype in women compared with men. Men had a significantly higher weight than women, and by using a fixed DM dose of $50 \mathrm{mg}$ instead of a weight-based dose, the CYP2D6 phenotype was higher in women compared with men. When corrected for weight, however, there was no difference in CYP2D6 phenotype between the groups.

To filter out the contribution of the CYP2D6 genotype, we calculated the CYP2D6 phenotype per genotype group in frail in non-frail subjects (Table 3); with more active CYP2D6 alleles, higher breath tests results were found. Because of the small subgroups, it is not possible to identify any difference in CYP2D6 phenotype within the subgroups.

Parameters that may be associated with drug metabolism were separately correlated to the Fried frailty score and the CYP2D6 phenotype (Table 4): BMI was negatively correlated to the phenotype $[-0.350(p=0.046)]$. With the knowledge that most patients had normal liver and renal function, liver tests and creatinine values were not

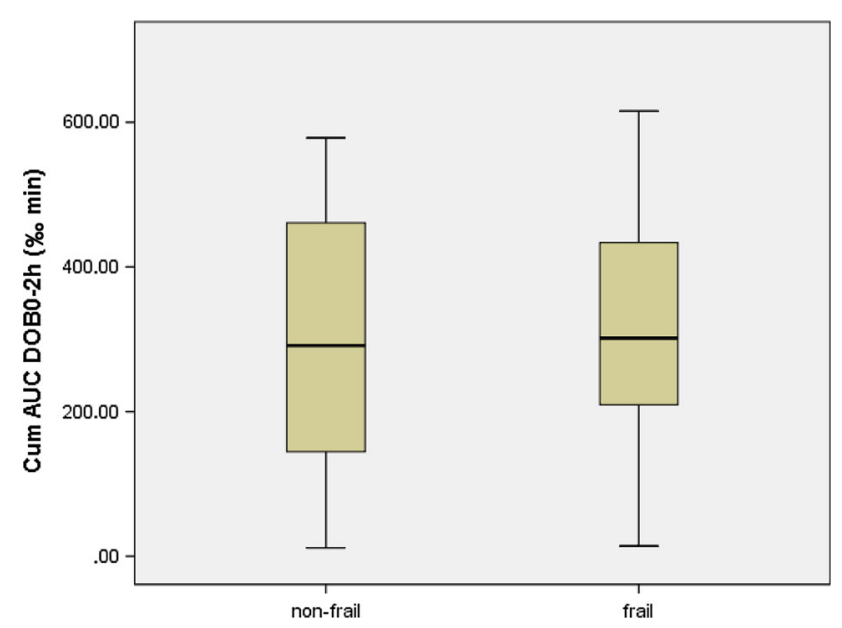

Fig. 1 Box plot of CYP2D6 phenotype measured by dextromethorphan breath test between frail and non-frail subjects. $A U C$ area under the curve, Cum cumulative, $D O B$ delta over baseline, \%o per mille 
Table 2 CYP2D6 phenotype by frailty subgroup

\begin{tabular}{|c|c|c|c|}
\hline & $\begin{array}{l}\text { DM-BT result }\left[\mathrm{AUC}_{\mathrm{DOB} 2 \mathrm{~h}}\right. \\
(\% \text { min })](\text { mean } \pm \mathrm{SD})\end{array}$ & No. & ANOVA \\
\hline \multicolumn{4}{|l|}{ Sex } \\
\hline Men & $252 \pm 142$ & 15 & $P=0.036($ men vs. women $)$ \\
\hline Women & $362 \pm 162$ & 18 & \\
\hline \multicolumn{4}{|l|}{ Frailty } \\
\hline Frail & $319 \pm 169$ & 11 & $P=0.728$ (frailty vs. non-frailty) \\
\hline Men & $276 \pm 168$ & 6 & $P=0.62($ frail men vs. non-frail men $)$ \\
\hline Women & $370 \pm 174$ & 5 & $P=0.982($ frail women vs. non-frail women $)$ \\
\hline Non-frail & $298 \pm 159$ & 22 & \\
\hline Men & $240 \pm 134$ & 12 & $P=0.059($ non-frail men vs. non-frail women $)$ \\
\hline Women & $367 \pm 165$ & 10 & \\
\hline
\end{tabular}

$A N O V A$ analysis of variance, $A U C_{D O B 2 h}$ area under the curve for delta over baseline values $(0-2 \mathrm{~h}), D M$ $B T{ }^{13} \mathrm{C}$-dextromethorphan breath test, $S D$ standard deviation
Table 3 CYP2D6 phenotype in non-frail and frail subjects by genotype

\begin{tabular}{lll}
\hline Genotype & $\begin{array}{l}\text { CYP2D6 phenotype }\left(\mathrm{AUC}_{\mathrm{DOB} 2 \mathrm{~h}}, \% \mathrm{~min}\right), \\
\text { mean } \pm \mathrm{SD} \text { in non-frail subjects }\end{array}$ & $\begin{array}{l}\text { CYP2D6 phenotype }\left(\mathrm{AUC}_{\mathrm{DOB} 2 \mathrm{~h}} \% \mathrm{~min}\right), \\
\text { mean } \pm \mathrm{SD} \text { in frail subjects }\end{array}$ \\
\hline $\mathrm{PM}$ & $74.3 \pm 57.4 ;(n=3)$ & na; $(n=0)$ \\
$\mathrm{IM}$ & $243.2 \pm 121.3 ;(n=7)$ & $330.8 \pm 134.4 ;(n=6, p=0.319)$ \\
$\mathrm{EM}$ & $397.0 \pm 148.8 ;(n=8)$ & $402.3 \pm 201.3 ;(n=3, p=0.684)$ \\
\hline
\end{tabular}

$A U C_{D O B 2 h}$ area under the curve for delta over baseline values $(0-2 \mathrm{~h})$, representing CYP2D6 phenotype, $E M$ extensive metabolizer, $I M$ intermediate metabolizer, $P M$ poor metabolizer, $n a$ not applicable correlated to CYP2D6 phenotype. With the use of a fixed DM dose of $50 \mathrm{mg}$, and because the mean weight in men $(82 \pm 9 \mathrm{~kg})$ was significantly higher than that in women $(69 \pm 13 \mathrm{~kg})$, we observed a higher CYP2D6 phenotype in women compared with men (Table 2).

Regarding separate parameters of frailty, Karnofsky score, ADL score, maximum grip strength and the time needed to walk $4 \mathrm{~m}$ were not correlated to CYP2D6 phenotype. The chair-stand test was positively correlated to the frailty score but negatively correlated to CYP2D6 phenotype [0.467 $(p=0.006)$ and $-0.372(p=0.039)$, respectively]. Dibucaine number, (free) testosterone and DHEAS levels in men were neither correlated to frailty nor to CYP2D6 phenotype. No correlation between frailty score, whether or not corrected for BMI, and CYP2D6 phenotype was identified.

\section{Discussion}

This is the first study investigating CYP2D6 phenotype in frail versus non-frail subjects by means of a non-invasive DM-BT phenotype test.

We hypothesized that CYP2D6 metabolism was decreased in frail elderly in line with the increased incidence of adverse drug reactions in frail subjects compared with non-frail subjects [16].

Consistent with a frail phenotype, functional scores (ADL, Karnofsky) were lower in the frail subgroup.
Despite the fact that no difference was observed in the time to stand up from a chair and in biochemical parameters associated with frailty, such as dibucaine and testosterone, between frail and non-frail subjects, the high combined frailty score in the frail elderly group was compatible with a frail population. In light of the absence of any Fried criteria in the non-frail group, we therefore considered that the frail and non-frail study participants were distinctive enough to test our hypothesis. BMI was negatively and significantly correlated to CYP2D6 metabolism, but even when frailty score was corrected for BMI, no difference in CYP2D6 phenotype was observed between the two groups.

The finding of absence of altered CYP2D6 activity in frail subjects is consistent with the study of Schwartz [5]. In this study, ERBTs to phenotype CYP3A were performed in 60 individuals aged 65-101 years, 27 of whom were classified as frail. Frail subjects did not display altered CYP3A metabolism compared with non-frail subjects. Phenoconversion, in which the phenotype is altered by concomitant use of CYP450 inhibitors or inducers, might alter phenotype results. In contrast to the study by Schwartz [5], however, concomitant medication such as CYP2D6 inhibitors and inducers were excluded in our study and could therefore not have biased our results. There are some limitations in this study. First, due to difficulties in recruiting frail patients, eventually 33 (11 frail, 22 non-frail) patients were invited for the study, a number less than originally calculated (21 vs. 21). Therefore, we performed a post hoc power analysis; 
Table 4 Correlation of specific parameters with frailty score and CYP2D6 phenotype

\begin{tabular}{|c|c|c|}
\hline Parameter & Pearson correlation with frailty score $(r)$ & Pearson correlation with $\mathrm{AUC}_{\mathrm{DOB} 2 \mathrm{~h}}(r)$ \\
\hline Gender & $0.07(p=0.714)$ & $0.366(p=0.036)^{*}$ \\
\hline BMI $\left(\mathrm{kg} / \mathrm{m}^{2}\right)$ & $0.10(p=0.585)$ & $-0.350(p=0.046)^{*}$ \\
\hline Karnofsky score & $0.86(p<0.001)^{*}$ & $0.152(p=0.397)$ \\
\hline MMSE score & $-0.143(p=0.426)$ & $0.288(p=0.104)$ \\
\hline HADS score & $0.510(p=0.013)^{*}$ & $0.185(p=0.400)$ \\
\hline ADL score & $0.603(p<0.001)^{*}$ & $-0.135(p=0.461)$ \\
\hline Max. grip strength (kg) & $-0.379(p=0.02)^{*}$ & $-0.028(p=0.873)$ \\
\hline 4-m walking time (s) & $0.467(p=0.006)^{*}$ & $-0.024(p=0.896)$ \\
\hline Chair-stand test (s) & $0.467(p=0.006)^{*}$ & $-0.372(p=0.039)^{*}$ \\
\hline \multicolumn{3}{|l|}{ Laboratory investigations } \\
\hline Dibucaine & $-0.021(p=0.909)$ & $-0.010(p=0.959)$ \\
\hline Testosterone & $0.045(p=0.868)$ & $-0.024(p=0.931)$ \\
\hline Free testosterone & $0.030(p=0.913)$ & $-0.43(p=0.874)$ \\
\hline DHEAS & $-0.195(p=0.293)$ & $0.002(p=0.994)$ \\
\hline LDH & $0.123(p=0.504)$ & $0.052(p=0.776)$ \\
\hline Bilirubin & $0.138(p=0.450)$ & $-0.219(p=0.229)$ \\
\hline ASAT & $0.248(p=0.171)$ & $-0.032(p=0.862)$ \\
\hline ALAT & $0.366(p=0.039)$ & $0.089(p=0.630)$ \\
\hline Creatinine & $-0.024(p=0.895)$ & $-0.180(p=0.324)$ \\
\hline Frailty score & & $-0.032(p=0.861)$ \\
\hline Corrected for BMI & & $0.030(p=0.987)$ \\
\hline
\end{tabular}

$A D L$ activities of daily living, $A L A T$ alanine aminotransferase, $A S A T$ aspartate aminotransferase, $A U C_{D O B 2 h}$ area under the curve for delta over baseline values (0-2 h), BMI body mass index, DHEAS dehydroepiandrostenedione sulfate, HADS Hospital Anxiety and Depression Scale, $L D H$ lactate dehydrogenase, MMSE Mini-Mental State Examination

* Correlation is significant at the 0.05 level (two tailed)

the calculated power with the pre-assumptions decreased from 80 to $61 \%$, which means that there was a $61 \%$ chance of detecting a statistically significant difference if it existed. In other words, the probability of a $p$ value of $>0.05$ is approximately $40 \%$. The present sample size is therefore considered too small to draw any firm conclusions regarding a potential phenoconversion of CYP2D6 in frail elderly as compared with healthy subjects.

Second, we applied the Fried criteria to assess frailty in our subjects. Although this phenotype model has been validated and generally accepted, potentially important factors such as cognitive impairment, a highly prevalent condition associated with functional decline and disability, have not been included in the Fried criteria. Although other models do in fact include such parameters, they have not been validated in clinical practice [17]. Lastly, the DM-BT has not been validated in an aged and/or frail population.

Frailty, as currently defined, can be considered representative of a generalized decline in function that can be predictive of the need for assistance or interventions to avoid dependency. The criteria do not include measures of medical disease severity or organ function but suggest a clinical syndrome.
Our findings do not suggest that the clinical syndrome of frailty as such is an important determinant of CYP2D6mediated drug metabolism. Since we did observe a large heterogeneity in CYP2D6 metabolism in women using tamoxifen in the adjuvant setting for breast cancer [8], predicting factors other than frailty might be more important. However, we cannot exclude that CYP2D6 induction or inhibition by several drugs could be altered with the presence of frailty.

Due to the fact that the study was underpowered to test our hypothesis, we cannot draw any conclusion regarding a potential impact of frailty on CYP2D6 metabolism. Further studies with more patients are needed in order to adequately understand a possible correlation.

Acknowledgments We are grateful to Cambridge Isotope Laboratories, Inc. for supplying the ${ }^{13} \mathrm{C}$-DM formulation, breath bags and POCone spectrophotometer for the study.

\section{Compliance with Ethical Standards}

Disclosures Dr. A. Modak is Associate Director Medical Products R\&D of Cambridge Isotope Laboratories, Inc., Andover, MA, USA. All other authors state that they have no conflict of interest. There was no financial support of any company to this study. 
Open Access This article is distributed under the terms of the Creative Commons Attribution-NonCommercial 4.0 International License (http://creativecommons.org/licenses/by-nc/4.0/), which permits any noncommercial use, distribution, and reproduction in any medium, provided you give appropriate credit to the original author(s) and the source, provide a link to the Creative Commons license, and indicate if changes were made.

\section{References}

1. Fried LP, Tangen CM, Walston J, et al. Frailty in older adults: evidence for a phenotype. J Gerontol A Biol Sci Med Sci. 2001;56:M146-56.

2. Walston J, Hadley EC, Ferrucci L, et al. Research agenda for frailty in older adults: toward a better understanding of physiology and etiology: summary from the American Geriatrics Society/National Institute on Aging Research Conference on Frailty in Older Adults. J Am Geriatr Soc. 2006;54:991-1001.

3. McLachlan AJ, Hilmer SN, Le Couteur DG. Variability in response to medicines in older people: phenotypic and genotypic factors. Clin Pharmacol Ther. 2009;85:431-3.

4. Hubbard RE, O'Mahony MS, Calver BL, Woodhouse KW. Plasma esterases and inflammation in ageing and frailty. Eur $\mathbf{J}$ Clin Pharmacol. 2008;64:895-900.

5. Schwartz JB. Erythromycin breath test results in elderly, very elderly, and frail elderly persons. Clin Pharmacol Ther. 2006;79:440-8.

6. Wynne HA, Cope LH, Herd B, Rawlins MD, James OF, Woodhouse KW. The association of age and frailty with paracetamol conjugation in man. Age Ageing. 1990;19:419-24.

7. Wynne HA, Yelland C, Cope LH, Boddy A, Woodhouse KW, Bateman DN. The association of age and frailty with the pharmacokinetics and pharmacodynamics of metoclopramide. Age Ageing. 1993;22:354-9.
8. Opdam FL, Dezentje VO, den Hartigh J, et al. The use of the ${ }^{13} \mathrm{C}$ dextromethorphan breath test for phenotyping CYP2D6 in breast cancer patients using tamoxifen: association with CYP2D6 genotype and serum endoxifen levels. Cancer Chemother Pharmacol. 2013;71:593-601.

9. Renton KW. Cytochrome P450 regulation and drug biotransformation during inflammation and infection. Curr Drug Metab. 2004;5:235-43.

10. Kinirons MT, Morike K, Shay S, Roden DM, Wood AJJ. Does selective-inhibition of cytochrome P450S occur with aging. Clin Res. 1994;42:A215.

11. Pollock BG, Perel JM, Reynolds CF, Altieri LP, Kirshner M. Clinical relevance of debrisoquine phenotyping in geriatric psychopharmacology. Clin Pharmacol Ther. 1992;51:175.

12. Leeder JS, Pearce RE, Gaedigk A, Modak A, Rosen DI. Evaluation of a $\left[{ }^{13} \mathrm{C}\right]$-dextromethorphan breath test to assess CYP2D6 phenotype. J Clin Pharmacol. 2008;48:1041-51.

13. Gaedigk A, Simon SD, Pearce RE, Bradford LD, Kennedy MJ, Leeder JS. The CYP2D6 activity score: translating genotype information into a qualitative measure of phenotype. Clin Pharmacol Ther. 2008;83:234-42.

14. Folstein MF, Folstein SE, McHugh PR. "Mini-mental state". A practical method for grading the cognitive state of patients for the clinician. J Psychiatr Res. 1975;12:189-98.

15. Weissman MM, Sholomskas D, Pottenger M, Prusoff BA, Locke BZ. Assessing depressive symptoms in five psychiatric populations: a validation study. Am J Epidemiol. 1977;106:203-14.

16. Lattanzio F, Landi F, Bustacchini S, et al. Geriatric conditions and the risk of adverse drug reactions in older adults: a review. Drug Saf. 2012;35(Suppl 1):55-61.

17. Clegg A, Young J, Iliffe S, Rikkert MO, Rockwood K. Frailty in elderly people. Lancet. 2013;381(9868):752-62. 